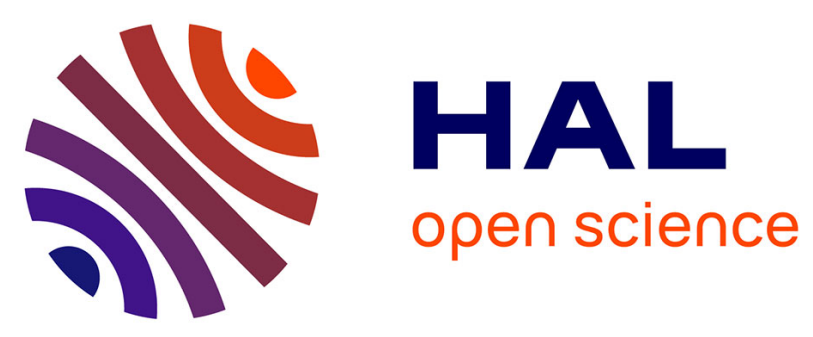

\title{
Geriatric Factors Predict Chemotherapy Feasibility: Ancillary Results of FFCD 2001-02 Phase III Study in First-Line Chemotherapy for Metastatic Colorectal Cancer in Elderly Patients
}

Thomas Aparicio, Jean-Louis Jouve, Laurent Teillet, Dany Gargot, Fabien Subtil, Valérie Le Brun-Ly, Jacques Cretin, Christophe Locher, Olivier Bouché, Gilles Breysacher, et al.

\section{- To cite this version:}

Thomas Aparicio, Jean-Louis Jouve, Laurent Teillet, Dany Gargot, Fabien Subtil, et al.. Geriatric Factors Predict Chemotherapy Feasibility: Ancillary Results of FFCD 2001-02 Phase III Study in First-Line Chemotherapy for Metastatic Colorectal Cancer in Elderly Patients. Journal of Clinical Oncology, 2013, 31 (11), pp.1464 - 1470. 10.1200/jco.2012.42.9894 . hal-03186380

\author{
HAL Id: hal-03186380 \\ https://hal.science/hal-03186380
}

Submitted on 31 Mar 2021

HAL is a multi-disciplinary open access archive for the deposit and dissemination of scientific research documents, whether they are published or not. The documents may come from teaching and research institutions in France or abroad, or from public or private research centers.
L'archive ouverte pluridisciplinaire HAL, est destinée au dépôt et à la diffusion de documents scientifiques de niveau recherche, publiés ou non, émanant des établissements d'enseignement et de recherche français ou étrangers, des laboratoires publics ou privés. 
Thomas Aparicio, Avicenne Hospital, Assistance Publique-Hopitaux de Paris (AP-HP), Université Paris 13, Sorbonne Paris Cité, Bobigny; Laurent Teillet, Sainte Perine Hospital, AP-HP; Emmanuel Mitry, Institut Curie, Versaille Saint Quentin University, Paris; Jean-Louis Jouve, Centre Hospitalier Universitaire (CHU) Dijon; Fabien Subtil, Fédération Francophone de Cancérologie Digestive, Dijon; Dany Gargot, Centre Hôspitalier (CH) Blois, Blois; Valérie Le Brun-Ly, CHU Limoges, Limoges; Jacques Cretin, CH Ales, Ales; Christophe Locher, $\mathrm{CH}$ Meaux, Meaux; Olivier Bouché, $\mathrm{CHU}$ Robert Debre, Reims; Gilles Breysacher, $\mathrm{CH}$ Colmar Colmar; Jacky Charneau, $\mathrm{CH}$ Boulogne-sur-Mer, Boulogne-sur-Mer; Jean-François Seitz, Timone Hospital, Assistance Publique-Hopitaux de Marseille (AP-HM); Mohamed Gasmi, Hôpital Nord, AP-HM, Marseille; Laetitia Stefani, $\mathrm{CH}$ Pringy, Pringy; Mohamed Ramdani, $\mathrm{CH}$ Bezier, Bezier; and Thierry Lecomte, $\mathrm{CHU}$ Trousseau, Université François-Rabelais, Tours, France.

Published online ahead of print at www.jco.org on March 4, 2013.

Supported by Grant No. WPO/N1720371 from Pfizer.

Presented at the 47th Annual Meeting of the American Society of Clinical Oncology, Chicago, IL, June 3-7, 2011.

Authors' disclosures of potential conflicts of interest and author contributions are found at the end of this

article.

Corresponding author: Thomas Aparicio $\mathrm{MD}, \mathrm{PhD}$, Gastroenterology, Avicenne Hospital, AP-HP, Université Paris 13, Sorbonne Paris Cité, 125 rue de Stalingrad, 93000 Bobigny, France; e-mail: thomas.aparicio@avc.aphp.fr.

() 2013 by American Society of Clinical Oncology

0732-183X/13/3111-1464/\$20.00 DOI: $10.1200 / J C O .2012 .42 .989$

\section{Geriatric Factors Predict Chemotherapy Feasibility: Ancillary Results of FFCD 2001-02 Phase III Study in First-Line Chemotherapy for Metastatic Colorectal Cancer in Elderly Patients}

Thomas Aparicio, Jean-Louis Jouve, Laurent Teillet, Dany Gargot, Fabien Subtil, Valérie Le Brun-Ly, Jacques Cretin, Christophe Locher, Olivier Bouché, Gilles Breysacher, Jacky Charneau, Jean-François Seitz, Mohamed Gasmi, Laetitia Stefani, Mohamed Ramdani, Thierry Lecomte, and Emmanuel Mitry

\section{$\begin{array}{llllllll}\text { A } & \text { B } & \text { S } & \text { T } & \text { R } & \text { A } & \text { C } & \text { T }\end{array}$}

\section{Purpose}

Elderly patients form a heterogeneous population. Evaluation of geriatric factors may help evaluate a patient's health status to better adapt treatment.

\section{Patients and Methods}

Elderly patients with previously untreated metastatic colorectal cancer (mCRC) were randomly assigned to receive fluorouracil (FU) -based chemotherapy either alone or in combination with irinotecan (IRI) in the Fédération Francophone de Cancérologie Digestive (FFCD) 2001-02 study. Sites participating in the geriatric substudy completed geriatric screening tools to perform prognostic factor analyses for treatment safety during the first 4 months after treatment initiation.

\section{Results}

The geriatric score was calculated in 123 patients (44\%). Median age was 80 years (range, 75 to 91 years). The Charlson comorbidity index was $\leq 1$ in $75 \%$, Mini-Mental State Examination (MMSE) score was $\leq 27 / 30$ in $31 \%$, and Instrumental Activities of Daily Living (IADL) showed impairment in 34\% of the patients. Seventy-one patients (58\%) had grade 3 to 4 toxicity, 41 (33\%) had a dose-intensity reduction of more than 33\%, and $54(44 \%)$ had at least one unexpected hospitalization during the first 4 months after starting treatment. In multivariate analysis, significant predictive factors for grade 3-4 toxicity were IRI arm (odds ratio [OR], 5.03), MMSE $\leq 27 / 30$ (OR, 3.84), and impaired IADL (OR, 4.67); for dose-intensity reduction of $>33 \%$, the significant predictive factors were alkaline phosphates $>2 \times$ upper limit of normal $(O R, 4.16)$ and IRI $\operatorname{arm}(\mathrm{OR}, 6.85)$; and for unexpected hospitalization, significant predictive factors were MMSE $\leq 27 / 30(O R, 4.56)$ and Geriatric Depression Scale $\leq 2$ (OR, 5.52).

\section{Conclusion}

Geriatric factors (MMSE and IADL) are predictive of severe toxicity or unexpected hospitalization (MMSE) in a randomized prospective phase III study in $\mathrm{mCRC}$. These results suggest that cognitive function and autonomy impairment should be taken into account when choosing a regimen for chemotherapy.

\section{J Clin Oncol 31:1464-1470. (C) 2013 by American Society of Clinical Oncology}

\section{INTRODUCTION}

Colorectal cancer occurs mainly in elderly patients. Recent estimates showed that in France, $45 \%$ of patients diagnosed with colorectal cancer were age 75 years or older. Specific data for the treatment of metastatic colorectal cancer (mCRC) in elderly patients are scarce. Until recently, elderly patients were under-represented in clinical trials. ${ }^{1}$ Moreover, the main studies that established the intensification of chemotherapy included few or highly selected elderly patients. ${ }^{2,3}$ In a series of selected elderly patients who were eligible for chemotherapy, irinotecan (IRI) or oxaliplatin combined with fluorouracil (FU) was well tolerated and was as effective as in younger patients. ${ }^{4}$ A post hoc analysis of randomized clinical trials comparing IRI and FU combined versus FU alone suggested that the benefits of IRI on progression-free survival and overall survival was preserved in patients older than age 70 years. ${ }^{5}$ However, those patients represented only $22 \%$ of the randomly assigned patients, and specific data for patients older than 75 years were not analyzed in that study. A prospective phase II study evaluated the 
FOLFIRI regimen [fluorouracil, leucovorin, and irinotecan] in patients older than 70 years and concluded that the treatment was well tolerated and effective in selected elderly patients. ${ }^{6}$ No geriatric evaluation was performed in that study.

The choice of the best treatment strategy is an important challenge in elderly patients. Balducci et $\mathrm{al}^{7}$ suggested tailoring treatment according to a specific geriatric evaluation. To date, the relevance of geriatric predictive factors has not been demonstrated in the management of mCRC.

The Fédération Francophone de Cancérologie Digestive (FFCD) 2001-02 trial was a randomized phase III study to evaluate IRI combined with FU versus FU alone in patients with mCRC age 75 years or older. The main end point, progression-free survival, is still under study. An ancillary study of geriatric parameters was performed to identify predictive factors of treatment feasibility and toxicity.

\section{PATIENTS AND METHODS}

\section{Patients and Treatments}

Elderly patients age 75 years or more with previously untreated mCRC were randomly assigned to receive FU-based chemotherapy either alone (as LV5FU2 [FU plus leucovorin] or as simplified LV5FU2) or in combination with IRI (as LV5FU2-CPT11 [LV5FU2-IRI] or FOLFIRI) from 2003 to 2010 (Fig 1). In the IRI arm, the first two cycles were performed with $150 \mathrm{mg} / \mathrm{m}^{2}$ of IRI and, in the absence of toxicity, the dose of IRI was increased to $180 \mathrm{mg} / \mathrm{m}^{2}$ for the following cycles. The randomization was performed by minimization, according to the following stratification factors: treatment center, Charlson index ( $0 v 1$ to $2 v 3$ or more), Karnofsky performance score (KPS; $100 v 90$ to $80 v 70$ to 60 ), previous adjuvant chemotherapy, sex, age ( $<80 v \geq 80$ years), and alkaline phosphatase ( $\leq 2 \times$ upper limit of normal [ULN] $v>2 \times \mathrm{ULN})$.

\section{Geriatric Assessment}

An ancillary geriatric study was planned in the FFCD 2001-02 trial, but the sample size was calculated for disease-free survival comparison and not for the geriatric parameters evaluation. The geriatric assessment was not mandatory. Thus, only hospitals with teams that volunteered to participate were included in the geriatric portion of the study. In the centers with volunteer teams, all consecutive patients were candidates for a geriatric assessment. Patients at these sites completed a visual analog scale of quality of life (QoL) at inclusion and the following geriatric questionnaires: Mini-Mental State Examination (MMSE) ${ }^{8}$ Instrumental Activities of Daily Living (IADL) scale, ${ }^{9}$ and Geriatric Depression Scale (GDS) ${ }^{10}$ to assess cognitive function, dependence, and depression, respectively. The associated scores were calculated; the score was considered missing when more than half the items were missing.

\section{Outcomes}

Three outcomes were particularly analyzed during the first 4 months after starting treatment: (1) at least one grade 3 to 4 toxicity, according to the National Cancer Institute Common Toxicity Criteria version 2.0 (NCI-CTC 2.0 ) scoring; (2) a dose-intensity reduction of $33 \%$ or more for at least one treatment; and (3) at least one hospitalization for any reason except trial chemotherapy perfusion. Geriatric scores as well as clinical and biologic tumor factors were analyzed to explore the predictive value of the aforementioned factors.

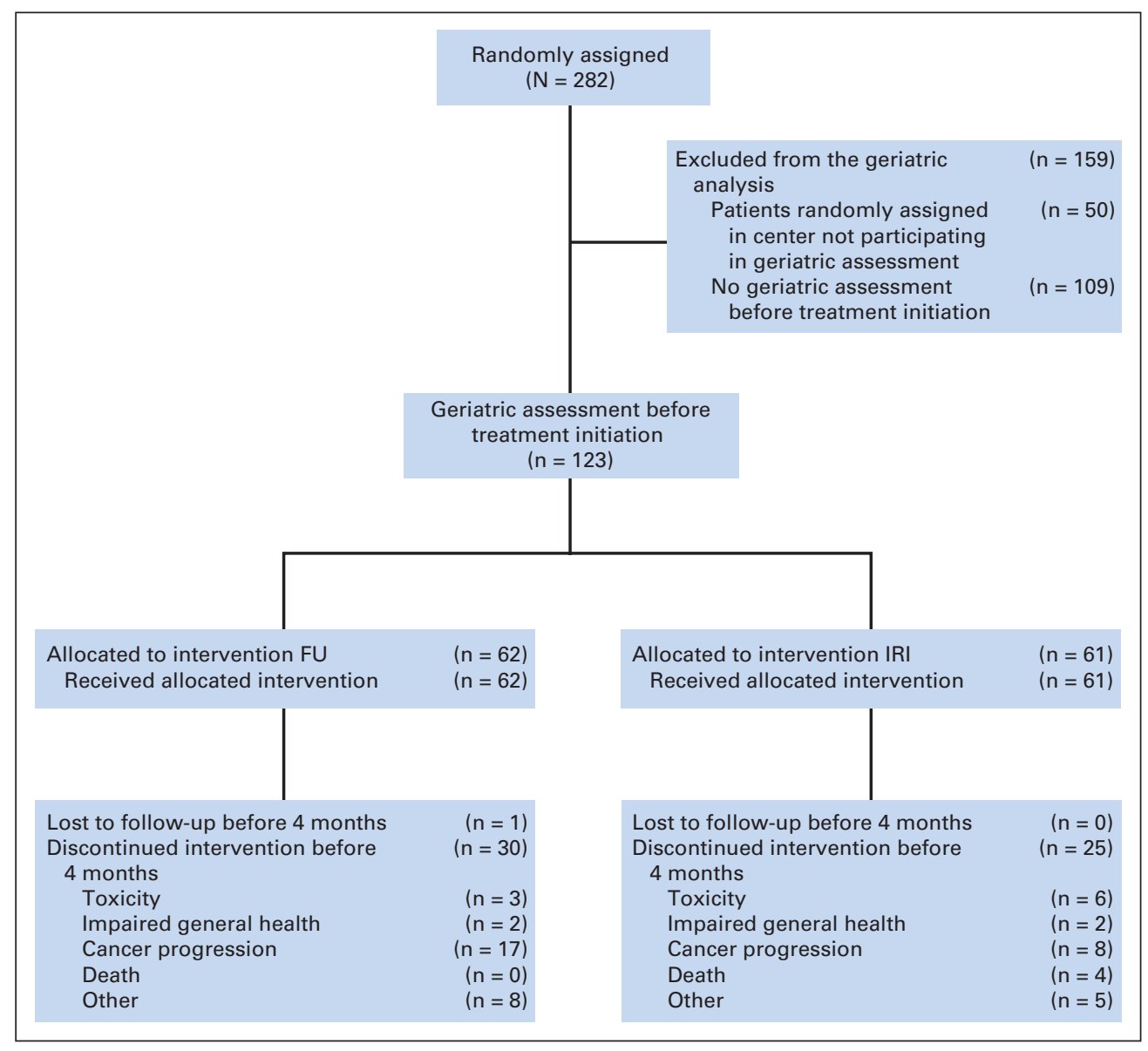

Fig 1. CONSORT diagram. FU, fluorouracil; IRI, irinotecan. 


\section{Statistical Analysis}

Logistic regressions were performed to analyze predictive factors. Those with a $P$ value below .20 in the univariate analyses were kept for multivariate analyses. The statistical software STATA version 10 (STATA, College Station, TX) was used for the analyses. The variables analyzed are listed in Table 1.

\section{RESULTS}

The FFCD 2001-02 trial enrolled 282 patients from 2003 to 2010. Fifty centers participated in the study, and among the 50 centers, 32 (64\%) participated in the geriatric study. Geriatric scores were calculated in 123 (44\%) of the 282 patients randomly assigned in the study. Among these patients, $62(50.4 \%)$ were allocated to the FU arm and 61
(49.6\%) to IRI arm. The characteristics of these 123 patients are described in Table 1. Liver metastases were present in 98 patients (80\%). Among these patients, 25 (25\%) had alkaline phosphatase level of more than $2 \times$ ULN.

Tumor and geriatric parameters were comparable in the FU and IRI arms, except there was a higher proportion of patients with more than two metastatic sites on the IRI arm $(26 \% v 11 \% ; P=.04)$ and a slightly higher proportion of patients with comorbidities assessed by the Charlson index in the IRI arm $(31 \% v 16 \% ; P=.06)$.

MMSE, GDS, and IADL results were unavailable for analysis (totally missing or more than half the items missing) for $26 \%, 27 \%$, and $29 \%$ of the patients, respectively. Globally, $31 \%$ of patients had at least one questionnaire missing or not usable.

\begin{tabular}{|c|c|c|c|c|c|c|c|c|c|}
\hline Characteristic & No. & $\%$ & Mean \pm SD & No. & $\%$ & Mean $\pm S D$ & No. & $\%$ & Mean \pm SD \\
\hline \multicolumn{10}{|l|}{ Sex } \\
\hline Male & 66 & 54 & & 33 & 53 & & 33 & 54 & \\
\hline Female & 57 & 46 & & 29 & 47 & & 28 & 46 & \\
\hline$\leq 2$ & 99 & 80 & & 55 & 89 & & 44 & 72 & \\
\hline$>2$ & 23 & 19 & & 7 & 11 & & 16 & 26 & \\
\hline Presence of liver metastases & 98 & 80 & & 49 & 79 & & 49 & 80 & \\
\hline \multicolumn{10}{|l|}{ Primary tumor resected } \\
\hline Yes & 83 & 67 & & 42 & 68 & & 41 & 67 & \\
\hline No & 39 & 32 & & 20 & 32 & & 19 & 31 & \\
\hline$\leq 2 \times$ ULN & 92 & 75 & & 44 & 71 & & 48 & 79 & \\
\hline$>2 \times$ ULN & 26 & 21 & & 15 & 24 & & 11 & 18 & \\
\hline \multicolumn{10}{|l|}{ Hemoglobin, g/dL } \\
\hline$\geq 10(\mathrm{~F}), \geq 11(\mathrm{M})$ & 15 & 12 & & 8 & 13 & & 7 & 11 & \\
\hline$<10(\mathrm{~F}),<11(\mathrm{M})$ & 107 & 87 & & 54 & 87 & & 53 & 87 & \\
\hline \multicolumn{10}{|l|}{ Karnofsky performance score } \\
\hline $60-70$ & 39 & 32 & & 21 & 34 & & 18 & 29 & \\
\hline $80-90$ & 62 & 50 & & 32 & 52 & & 30 & 49 & \\
\hline 100 & 20 & 16 & & 8 & 13 & & 12 & 20 & \\
\hline \multicolumn{10}{|l|}{ Charlson index } \\
\hline $0-1$ & 92 & 75 & & 51 & 82 & & 41 & 67 & \\
\hline$>1$ & 29 & 24 & & 10 & 16 & & 19 & 31 & \\
\hline Not evaluated & 33 & 27 & & 19 & 31 & & 14 & 23 & \\
\hline \multicolumn{10}{|l|}{ IADL } \\
\hline Impaired & 42 & 34 & & 22 & 35 & & 20 & 33 & \\
\hline Nonimpaired & 45 & 37 & & 22 & 35 & & 23 & 38 & \\
\hline Not evaluated & 36 & 29 & & 18 & 29 & & 18 & 29 & \\
\hline
\end{tabular}

Abbreviations: F, female: FU, fluorouracil; GDS, Geriatric Depression Scale; IADL, Instrumental Activities of Daily Living; IRI, irinotecan; M, male; MMSE, Mini-Mental State Examination; QoL, quality of life; SD, standard deviation; ULN, upper limit of normal; VAS, visual analog scale. 


\section{Toxicity}

Toxicity was analyzable in 122 patients. Seventy-one patients $(58 \%)$ had grade 3 to 4 toxicity during the first 4 months after starting treatment: 28 (39\%) in the FU arm and $43(61 \%)$ in the IRI arm. Results of the univariate analyses are presented in Table 2 . In the multivariate analysis, significant independent predictive factors of

\begin{tabular}{|c|c|c|c|}
\hline Variable & OR & $95 \% \mathrm{Cl}$ & $P$ \\
\hline Age, years & & & .623 \\
\hline$\leq 80$ & - & - & \\
\hline$>80$ & 1.20 & 0.58 to 2.50 & \\
\hline Sex & & & .106 \\
\hline Male & - & - & \\
\hline Female & 1.83 & 0.88 to 3.82 & \\
\hline Body mass index, $\mathrm{kg} / \mathrm{m}^{2}$ & & & .805 \\
\hline $20-30$ & - & - & \\
\hline$\leq 20$ & 1.01 & 0.21 to 4.75 & \\
\hline$>30$ & 1.52 & 0.43 to 5.36 & \\
\hline No. of metastatic sites & & & .745 \\
\hline$\leq 2$ & - & - & \\
\hline$>2$ & 1.17 & 0.46 to 2.95 & \\
\hline Liver metastases & & & .683 \\
\hline No & - & - & \\
\hline Yes & 1.21 & 0.49 to 2.96 & \\
\hline Primary tumor resected & & & .083 \\
\hline Yes & - & - & \\
\hline No & 2.04 & 0.91 to 4.57 & \\
\hline Previous adjuvant chemotherapy & & & .005 \\
\hline Yes & - & - & \\
\hline No & 5.56 & 1.69 to 18.27 & \\
\hline Alkaline phosphatase & & & .809 \\
\hline$\leq 2 \times U L N$ & - & - & \\
\hline$>2 \times$ ULN & 0.89 & 0.38 to 2.18 & \\
\hline Hemoglobin, g/dL & & & .705 \\
\hline$\geq 10(\mathrm{~F}), \geq 11(\mathrm{M})$ & - & - & \\
\hline$<10(\mathrm{~F}),<11(\mathrm{M})$ & 1.23 & 0.42 to 3.65 & \\
\hline Karnofsky performance score & & & .736 \\
\hline$>70$ & - & - & \\
\hline$\leq 70$ & 0.87 & 0.40 to 1.90 & \\
\hline Charlson index & & & .771 \\
\hline$\leq 1$ & - & - & \\
\hline$>1$ & 0.88 & 0.38 to 2.03 & \\
\hline QoL VAS, mm & & & .279 \\
\hline$>70$ & - & - & \\
\hline$\leq 70$ & 1.52 & 0.71 to 3.25 & \\
\hline Treatment arm & & & .003 \\
\hline FU & - & - & \\
\hline$|R|$ & 3.07 & 1.45 to 6.51 & \\
\hline MMSE & & & .013 \\
\hline$>27 / 30$ & - & - & \\
\hline$\leq 27 / 30$ & 3.08 & 1.27 to 7.51 & \\
\hline GDS & & & .066 \\
\hline$>2$ & - & - & \\
\hline$<2$ & 3.27 & 0.92 to 11.55 & \\
\hline IADL & & & .005 \\
\hline $8 / 8$ & - & - & \\
\hline$\leq 7 / 8$ & 3.62 & 1.47 to 8.91 & \\
\hline
\end{tabular}

Abbreviations: F, female; FU, fluorouracil; GDS, Geriatric Depression Scale; IADL, Instrumental Activities of Daily Living; IRI, irinotecan; M, male; MMSE, Mini-Mental State Examination; OR, odds ratio; QoL, quality of life; ULN, upper limit of normal; VAS, visual analog scale.

\begin{tabular}{|c|c|c|c|}
\hline Predictive Factor & OR & $95 \% \mathrm{Cl}$ & $P$ \\
\hline Female & 1.53 & 0.50 to 4.71 & .454 \\
\hline Primary tumor not resected & 1.20 & 0.34 to 4.21 & .779 \\
\hline No previous adjuvant chemotherapy & 3.85 & 0.67 to 22.03 & .130 \\
\hline Irinotecan arm & 5.03 & 1.61 to 15.77 & .006 \\
\hline Impaired cognitive function (MMSE $\leq 27 / 30$ ) & 3.84 & 1.24 to 11.84 & .019 \\
\hline Impaired autonomy (IADL) & 4.67 & 1.42 to 15.32 & .011 \\
\hline Better mood & 0.41 & 0.12 to 1.36 & .145 \\
\hline
\end{tabular}

grade 3 to 4 toxicity were IRI arm, MMSE, and impaired IADL (Table 3). An MMSE $\leq 27 / 30$ or an impaired IADL results in an OR of 5.43 (range, 2.09 to $14.11 ; P=.001$ ) for grade 3 to 4 toxicity.

\section{Dose Reduction}

The reduction in dose-intensity was analyzable in 122 patients. Forty-one patients (33\%) had a reduction in dose-intensity of more than 33\% during the first 4 months after starting treatment: $13(32 \%)$ in the FU arm and $28(68 \%)$ in the IRI arm. The results of the univariate analyses are presented in Table 4 . In the multivariate analysis, the significant independent predictive factors for a reduction in dose-intensity of more than $33 \%$ were IRI arm and alkaline phosphatase more than $2 \times$ ULN (Table 5).

\section{Hospitalization}

Hospitalization was analyzable in 118 patients. Fifty-four patients $(44 \%)$ had at least one unexpected hospitalization during the first 4 months after starting treatment: 29 (54\%) in the FU arm and 25 (46\%) in IRI arm. These 54 patients had 94 hospitalizations during the study period. The main reasons for hospitalization were supportive care (43 patients), toxicities (21 patients), surgery (nine patients), infection (eight patients), cardiovascular disease (four patients), and other (nine patients).

The results of the univariate analyses are presented in Appendix Table A1 (online only). In the multivariate analysis, significant independent predictive factors of hospitalization were an MMSE $\leq 27 / 30$ and a GDS score $\leq 2$ (Appendix Table A2, online only).

\section{Predictive Value of Geriatric Parameters According to Treatment Group}

For severe toxicity, the predictive effect of MMSE was similar in the FU and IRI arms (no statistical interaction; $P=.361$ ). In patients with an MMSE $\leq 27 / 30,89 \%$ (17 patients) in the IRI arm had grade 3 to 4 toxicity versus $50 \%$ (nine patients) in the FU arm. In patients with an MMSE of more than 27/30, 58\% (15 patients) in the IRI arm had grade 3 to 4 toxicity versus $30 \%$ (eight patients) in the FU arm.

The predictive effect of IADL for severe toxicity was also similar in the FU and IRI arms (no statistical interaction; $P=.664$ ). In patients with an impaired IADL, 89\% (17 patients) in the IRI arm had grade 3 to 4 toxicity versus $55 \%$ (12 patients) in the FU arm. In patients with a normal IADL, 56\% (13 patients) in the IRI arm had grade 3 to 4 toxicity versus $23 \%$ ( 5 patients) in the FU arm.

The combination of an impaired IADL and an MMSE $\leq 27 / 30$ also had a similar predictive effect in each arm (no statistical interaction; $P=.666$ ). In patients with an impaired IADL and an MMSE 


\begin{tabular}{|c|c|c|c|}
\hline Variable & OR & $95 \% \mathrm{Cl}$ & $P$ \\
\hline Age, years & & & .329 \\
\hline$\leq 80$ & - & - & \\
\hline$>80$ & 1.46 & 0.68 to 3.11 & \\
\hline Sex & & & .276 \\
\hline Male & - & - & \\
\hline Female & 1.52 & 0.71 to 3.24 & \\
\hline Body mass index, $\mathrm{kg} / \mathrm{m}^{2}$ & & & .424 \\
\hline $20-30$ & - & - & \\
\hline$\leq 20$ & 0.70 & 0.13 to 3.64 & \\
\hline$>30$ & 2.09 & 0.63 to 6.98 & \\
\hline No. of metastatic sites & & & .040 \\
\hline$\leq 2$ & - & - & \\
\hline$>2$ & 2.63 & 1.04 to 6.64 & \\
\hline Liver metastases & & & .608 \\
\hline No & - & - & \\
\hline Yes & 1.29 & 0.49 to 3.41 & \\
\hline Primary tumor resected & & & .649 \\
\hline Yes & - & - & \\
\hline No & 0.83 & 0.36 to 1.87 & \\
\hline Previous adjuvant chemotherapy & & & .895 \\
\hline Yes & - & - & \\
\hline No & 0.93 & 0.32 to 2.72 & \\
\hline Hemoglobin, g/dL & & & .981 \\
\hline$\geq 10(\mathrm{~F}), \geq 11(\mathrm{M})$ & - & - & \\
\hline$<10(\mathrm{~F}),<11(\mathrm{M})$ & 1.01 & 0.32 to 3.19 & \\
\hline Alkaline phosphatase & & & .017 \\
\hline$\leq 2 \times$ ULN & - & - & \\
\hline$>2 \times$ ULN & 2.96 & 1.21 to 7.24 & \\
\hline Karnofsky performance score & & & .464 \\
\hline$>70$ & - & - & \\
\hline$\leq 70$ & 1.34 & 0.61 to 2.98 & \\
\hline Charlson index & & & .710 \\
\hline$\leq 1$ & - & - & \\
\hline$>1$ & 0.84 & 0.34 to 2.07 & \\
\hline QoL VAS scale, mm & & & .062 \\
\hline$>70$ & - & - & \\
\hline$\leq 70$ & 2.24 & 0.96 to 5.22 & \\
\hline Treatment arm & & & .003 \\
\hline FU & - & - & \\
\hline$|\mathrm{R}|$ & 3.30 & 1.49 to 7.30 & \\
\hline MMSE & & & .127 \\
\hline$>27 / 30$ & - & - & \\
\hline$\leq 27 / 30$ & 2.97 & 0.73 to 12.02 & \\
\hline GDS & & & .626 \\
\hline$>2$ & - & - & \\
\hline$\leq 2$ & 0.74 & 0.22 to 2.49 & \\
\hline IADL & & & .188 \\
\hline $8 / 8$ & - & - & \\
\hline$\leq 7 / 8$ & 1.89 & 0.73 to 4.87 & \\
\hline
\end{tabular}

Abbreviations: F, female; FU, fluorouracil; GDS, Geriatric Depression Scale; IADL, Instrumental Activities of Daily Living: IRI, irinotecan: M, male: MMSE, Mini-Mental State Examination; OR, odds ratio; QoL, quality of life; ULN, upper limit of normal; VAS, visual analog scale.

$\leq 27 / 30,89 \%$ (25 patients) in the IRI arm had grade 3 to 4 toxicity versus $50 \%$ (15 patients) in the FU arm. In patients with normal IADL and MMSE more than 27/30, 44\% (seven patients) in the IRI arm had grade 3 to 4 toxicity versus $13 \%$ (two patients) in the FU arm.

In the FU arm, an unexpected hospitalization occurred in 11 (61\%) patients with an MMSE $\leq 27 / 30$ versus nine (35\%) patients

\begin{tabular}{|c|c|c|c|}
\hline Predictive Factor & OR & $95 \% \mathrm{Cl}$ & $P$ \\
\hline No. of metastases $>2$ & 1.50 & 0.36 to 6.14 & .575 \\
\hline Alkaline phosphatase level $>2 \mathrm{~N}$ & 4.16 & 1.02 to 16.94 & .047 \\
\hline Irinotecan arm & 6.86 & 1.85 to 25.39 & .004 \\
\hline Poor QoL (VAS $\leq 70)$ & 2.99 & 0.82 to 10.94 & .097 \\
\hline Impaired cognitive functions (MMSE $\leq 27 / 30$ ) & 2.25 & 0.40 to 12.49 & .355 \\
\hline Impaired autonomy (IADL) & 1.33 & 0.369 to 4.50 & .646 \\
\hline \multicolumn{4}{|c|}{$\begin{array}{l}\text { Abbreviations: IADL, Instrumental Activities of Daily Living; MMSE, Mini- } \\
\text { Mental State Examination; OR, odds ratio; QoL, quality of life; VAS, visual } \\
\text { analog scale. }\end{array}$} \\
\hline
\end{tabular}

with an MMSE more than 27/30. In the IRI arm, an unexpected hospitalization occurred in 12 patients (67\%) with an MMSE $\leq 27 / 30$ versus nine (36\%) patients with an MMSE more than 27/30. There was no significant interaction between the treatment arm and MMSE for unexpected hospitalizations $(P=.843)$.

\section{Exploratory Analysis With No Threshold for Geriatric Parameters}

Because no geriatric parameters were significant in the multivariate analyses with the usual thresholds for the reduction in doseintensity, a multivariate exploratory analysis was performed for IADL and MMSE considering them as continuous variables without a threshold. In the associated multivariate analysis, a linear decrease in MMSE was an independent prognostic factor of a reduction in doseintensity with an OR of 24.33 (95\% CI, 1.46 to 4,073.53) for every $10 \%$ decrease $(P=.035)$.

\section{DISCUSSION}

The choice of the best therapeutic strategy for mCRC is a major challenge in elderly patients. To the best of our knowledge, this is the first randomized prospective study performed specifically in patients with mCRC who are age 75 years or older. The main end point of the randomized trial was the evaluation of progression-free survival according to the treatment allocated. A geriatric assessment was performed in some of the centers as an ancillary study.

It has been claimed that geriatric assessments are useful when considering various therapies. ${ }^{11-13}$ However, the majority of the studies supporting this assertion were performed in heterogeneous populations in terms of tumor type and stage, or on a small number of patients. ${ }^{14,15}$ But each cancer type has its own prognosis, which means that the results of heterogeneous studies cannot be generalized. There are few data about geriatric assessment in mCRC.

Good tolerance to chemotherapy is important for elderly patients. ${ }^{16,17}$ The benefits of low toxicity and few unexpected hospitalizations during treatment need to be considered when a chemotherapy regimen is chosen. Moreover, because the planned dose-intensity reflects the feasibility of the treatment, it too should be evaluated. A delay of 4 months after starting the treatment was chosen for this evaluation. At that point, dose adaptations and severe toxicity as a result of patient frailty had usually already occurred and only a few patients experienced disease progression. 
Our results showed that some factors assessed with specific geriatric evaluation could predict toxicity and the feasibility of the treatment. Dependence is significantly associated with severe toxicity. It must be pointed out that dependent patients in both the FU and IRI arms were significantly more likely to experience toxicity. Dependence was found to be a predictive factor of chemotherapy-related toxicity in a prospective trial in advanced ovarian cancer. ${ }^{18}$ Dependence was associated with survival in a large phase III study in non-small-cell lung cancer ${ }^{19}$ but not in the Freyer et al study. ${ }^{18}$ There was no significant association between dependence and reductions in treatment dose-intensity or unexpected hospitalization in our study, but there was a trend toward a greater likelihood of both. A lack of power could explain why our results fell short of significance. Another explanation for the insignificant results is that the overall proportion of grade 3 to 4 toxicities was near $60 \%$, whereas the overall proportion of dose reduction of at least one third of the planned dose was only 33\% (and around $44 \%$ for unexpected hospitalization). These varying rates might explain in part the fact that IADL was found to be prognostic for toxicities but not for dose reductions. In another pilot prospective study involving all types of digestive cancer, it was suggested that dependence was associated with failure of the planned treatment, but again the results did not reach statistical significance. ${ }^{20}$ Indeed, our results support the empirical decision-making process that associates lower functional scores with a modification in cancer treatment. ${ }^{21}$

Impaired cognitive function predicts both toxicity and unexpected hospitalization. This is the first study to show that impaired cognitive function was a predictor of tolerance to chemotherapy. Almost $90 \%$ of patients with impaired cognitive function or impaired autonomy treated with IRI experienced severe toxicity. Regarding percentages, patients with an MMSE more than 27/30 and an unimpaired IADL can benefit from IRI without being more likely to experience toxicity than patients with an MMSE $\leq 27 / 30$ or impaired IADL treated with FU only. This result should be taken into account when deciding on a chemotherapy regimen. In patients with impaired cognitive function, there was only a trend toward a decrease in doseintensity. Nevertheless, MMSE was an independent predictor of dose reduction when analyzed as a continuous variable.

Depression was not associated with toxicity, as was shown in the Freyer et al study. ${ }^{18}$ In that study, however, depression was not assessed with the GDS but only according to the investigator's opinion. Surprisingly, a better mood was significantly associated with unexpected hospitalization. This unexpected result suggests that the GDS score should be used with caution in the metastatic setting.

Body mass index was not a predictor of toxicity or a reduction in dose-intensity, even in univariate analyses. Nevertheless, nutritional status is probably an important factor that should be considered before choosing a chemotherapy regimen. ${ }^{22}$ Unfortunately, no intensive nutritional investigation was planned in this study. We cannot exclude the possibility that a nutritional assessment could predict chemotherapy toxicity or dose-intensity.

Baseline QoL evaluations were not associated with toxicity, reductions in dose-intensity, or unexpected hospitalization in multivariate analyses. It must be pointed out that baseline QoL evaluations that used the European Organisation for Research and Treatment of Cancer Quality of Life Questionnaire-Core 30 (EORTC QLQ-C30) have already been described as a predictor of survival ${ }^{19,23}$ but have not been explored for predictions of toxicity.
The Charlson index or Karnofsky performance score did not predict toxicity or reductions in dose-intensity in our study. In esophageal cancer, the Charlson index was recently reported as a predictive factor of tolerance to radiochemotherapy. ${ }^{24}$ In our study, the large majority of patients were elderly but eligible for evaluation, and the value of several comorbidities could not be excluded. Age older than 80 years was not associated with toxicity or dose-intensity as was reported previously. ${ }^{4}$

IRI combined with FU chemotherapy was associated with increased toxicity and reductions in dose-intensity. The survival results are awaited to determine whether or not this dose reduction impaired survival. This underlines the need for careful selection of patients to be treated with intensive chemotherapy.

The alkaline phosphatase level is predictive of reductions in doseintensity. An increased level of alkaline phosphatase is known to be predictive of survival ${ }^{25}$ but has never been found to be predictive of dose-intensity. Reductions in dose-intensity were observed in both the FU and IRI arms, so it does not appear to be related to the hepatic metabolism of IRI alone. An increased level of alkaline phosphatase might reflect the liver tumor burden.

In our study, baseline hemoglobin level was not predictive of severe toxicity, chemotherapy dose reduction, or unexpected hospitalization. In two recent studies, ${ }^{26,27}$ initial hemoglobin level predicted chemotherapy toxicity. Our study had the same proportion of anemic patients as the study by Hurria et al. ${ }^{27}$ In our study, the chemotherapy regimen used might have been less toxic than the chemotherapy regimen used in the two recent studies. Another hypothesis is that, in our study, patients received more supportive care in the form of blood transfusions or erythropoietin treatment after enrollment.

In this study, only $64 \%$ of the centers participated in the ancillary geriatric study. This suggests that geriatric assessments are not performed routinely; even in participating centers, geriatric assessments were only partially completed for $30 \%$ of patients. Mini geriatric evaluations that could be done by the oncologist could probably help select suitable patients. ${ }^{20,28}$ A screening tool has been proposed to assess geriatric patients with cancer for comprehensive evaluation, ${ }^{29}$ and two chemotherapy risk assessment scales for elderly patients have recently been established ${ }^{26,27}$ and have shown good predictive value for estimating toxicity risk of chemotherapy in patients treated for several cancer types and stages. It should be noted that IADL impairment is among the most important items in both models established by Extermann et al and Hurria et al, and MMSE impairment is involved in one of them. Even with the significant improvements that have recently been made, predictive scales for chemotherapy toxicity are still a matter of debate, ${ }^{30}$ and it is important to validate geriatric predictive factors of chemotherapy toxicity in prospective trials. Our results suggesting that IADL and MMSE impairment are predictive of chemotherapy toxicity are in line with those of previous studies. Moreover, we describe the toxicity risk in a single population treated for mCRC according to chemotherapy regimen. Because the FFCD 2001-02 trial was not powered for the ancillary geriatric study, some inconsistencies may be due to inadequate power, and they emphasize the difficulty of conducting this type of study in elderly patients.

These results are from an exploratory analysis. The large number of predictive factors analyzed and the small number of patients with a complete geriatric assessment led to some spurious results, possibly due to overfitting. Hence, a further study is necessary to confirm these findings, but this analysis has revealed some trends. After patient screening, as it is done in our study or with a specific tool such as $\mathrm{G} 8,{ }^{29}$ 
if the patient is found to be impaired, a comprehensive geriatric assessment and a geriatric intervention are in order to aid the choice of appropriate treatment. Indeed, comprehensive geriatric assessment may lead to changes in planned cancer treatment. ${ }^{21}$

In conclusion, our study is the first to prospectively demonstrate that geriatric characteristics are independent predictive factors of tolerance to chemotherapy and toxicity in mCRC. Intensive chemotherapy should be used with caution in patients who have cognitive impairment or dependency. Larger studies are needed to confirm our results.

\section{AUTHORS' DISCLOSURES OF POTENTIAL CONFLICTS OF INTEREST}

Although all authors completed the disclosure declaration, the following author(s) and/or an author's immediate family member(s) indicated a financial or other interest that is relevant to the subject matter under consideration in this article. Certain relationships marked with a " $U$ " are those for which no compensation was received; those relationships marked with a " $C$ " were compensated. For a detailed description of the disclosure categories, or for more information about ASCO's conflict of interest policy, please refer to the Author Disclosure Declaration and the Disclosures of Potential Conflicts of Interest section in Information for Contributors.
Employment or Leadership Position: None Consultant or Advisory Role: None Stock Ownership: None Honoraria: Thomas Aparicio, Pfizer; Olivier Bouché, Pfizer; Jean-François Seitz, Pfizer; Emmanuel Mitry, Pfizer Research Funding: None Expert Testimony: None Other Remuneration: None

\section{AUTHOR CONTRIBUTIONS}

Conception and design: Thomas Aparicio, Emmanuel Mitry Provision of study materials or patients: Thomas Aparicio, Jean-Louis Jouve, Dany Gargot, Valérie Le Brun-Ly, Jacques Cretin, Christophe Locher, Olivier Bouché, Gilles Breysacher, Jacky Charneau, Jean-François Seitz, Mohamed Gasmi, Laetitia Stefani, Mohamed Ramdani, Thierry Lecomte, Emmanuel Mitry

Collection and assembly of data: Thomas Aparicio, Jean-Louis Jouve, Dany Gargot, Valérie Le Brun-Ly, Jacques Cretin, Christophe Locher, Olivier Bouché, Gilles Breysacher, Jacky Charneau, Jean-François Seitz, Mohamed Gasmi, Laetitia Stefani, Mohamed Ramdani, Thierry Lecomte, Emmanuel Mitry

Data analysis and interpretation: Thomas Aparicio, Laurent Teillet, Fabien Subtil, Emmanuel Mitry

Manuscript writing: All authors

Final approval of manuscript: All authors

\section{REFERENCES}

1. Yee KW, Pater JL, Pho L, et al: Enrollment of older patients in cancer treatment trials in Canada: Why is age a barrier? J Clin Oncol 21:1618-1623, 2003

2. de Gramont A, Figer $A$, Seymour $M$, et al: Leucovorin and fluorouracil with or without oxaliplatin as first-line treatment in advanced colorectal cancer. J Clin Oncol 18:2938-2947, 2000

3. Douillard JY, Cunningham D, Roth AD, et al: Irinotecan combined with fluorouracil compared with fluorouracil alone as first-line treatment for metastatic colorectal cancer: A multicentre randomised trial. Lancet 355:1041-1047, 2000

4. Aparicio $T$, Desramé $J$, Lecomte $T$, et al: Oxaliplatin- or irinotecan-based chemotherapy for metastatic colorectal cancer in the elderly. $\mathrm{Br} J$ Cancer 89:1439-1444, 2003

5. Folprecht G, Seymour MT, Saltz L, et al: Irinotecan/fluorouracil combination in first-line therapy of older and younger patients with metastatic colorectal cancer: Combined analysis of 2,691 patients in randomized controlled trials. J Clin Oncol 26:1443-1451, 2008

6. François E, Berdah JF, Chamorey E, et al: Use of the folinic acid/5-fluorouracil/irinotecan (FOLFIRI 1) regimen in elderly patients as a first-line treatment for metastatic colorectal cancer: A phase II study. Cancer Chemother Pharmacol 62:931-936, 2008

7. Balducci L, Extermann M: Management of cancer in the older person: A practical approach. Oncologist 5:224-237, 2000

8. Cockrell JR, Folstein MF: Mini-Mental State Examination (MMSE). Psychopharmacol Bull 24: 689-692, 1988

9. Lawton MP, Brody EM: Assessment of older people: Self-maintaining and instrumental activities of daily living. Gerontologist 9:179-186, 1969

10. Clément JP, Nassif RF, Léger JM, et al: [Development and contribution to the validation of a brief French version of the Yesavage Geriatric Depression Scale] [In French.] Encephale 23:91-99, 1997
11. Balducci $L$, Beghe $C$ : The application of the principles of geriatrics to the management of the older person with cancer. Crit Rev Oncol Hematol 35:147-154, 2000

12. Brunello A, Sandri R, Extermann M: Multidimensional geriatric evaluation for older cancer patients as a clinical and research tool. Cancer Treat Rev 35:487-492, 2009

13. Rodin MB, Mohile SG: A practical approach to geriatric assessment in oncology. J Clin Oncol 25: 1936-1944, 2007

14. Extermann M, Meyer J, McGinnis M, et al: A comprehensive geriatric intervention detects multiple problems in older breast cancer patients. Crit Rev Oncol Hematol 49:69-75, 2004

15. Girre V, Falcou MC, Gisselbrecht M, et al: Does a geriatric oncology consultation modify the cancer treatment plan for elderly patients? J Gerontol A Biol Sci Med Sci 63:724-730, 2008

16. Extermann M, Albrand G, Chen $\mathrm{H}$, et al: Are older French patients as willing as older American patients to undertake chemotherapy? J Clin Oncol 21:3214-3219, 2003

17. Yellen SB, Cella DF, Leslie WT: Age and clinical decision making in oncology patients. J Natl Cancer Inst 86:1766-1770, 1994

18. Freyer G, Geay JF, Touzet S, et al: Comprehensive geriatric assessment predicts tolerance to chemotherapy and survival in elderly patients with advanced ovarian carcinoma: A GINECO study. Ann Oncol 16:1795-1800, 2005

19. Maione P, Perrone F, Gallo $C$, et al: Pretreatment quality of life and functional status assessment significantly predict survival of elderly patients with advanced non-small-cell lung cancer receiving chemotherapy: A prognostic analysis of the multicenter Italian lung cancer in the elderly study. J Clin Oncol 23:6865-6872, 2005

20. Aparicio T, Girard L, Bouarioua N, et al: A mini geriatric assessment helps treatment decision in elderly patients with digestive cancer: A pilot study. Crit Rev Oncol Hematol 77:63-69, 2011

21. Caillet $P$, Canoui-Poitrine $F$, Vouriot $J$, et al: Comprehensive geriatric assessment in the decision-making process in elderly patients with cancer: ELCAPA study. J Clin Oncol 29:3636-3642, 2011

22. Blanc-Bisson $C$, Fonck $M$, Rainfray $M$, et al: Undernutrition in elderly patients with cancer: Target for diagnosis and intervention. Crit Rev Oncol Hematol 67:243-254, 2008

23. Efficace F, Bottomley A, Coens $C$, et al: Does a patient's self-reported health-related quality of life predict survival beyond key biomedical data in advanced colorectal cancer? Eur J Cancer 42:42-49, 2006

24. Tougeron D, Di Fiore F, Thureau $S$, et al: Safety and outcome of definitive chemoradiotherapy in elderly patients with oesophageal cancer. $\mathrm{Br} \mathrm{J}$ Cancer 99:1586-1592, 2008

25. Mitry E, Douillard JY, Van Cutsem E, et al: Predictive factors of survival in patients with advanced colorectal cancer: An individual data analysis of 602 patients included in irinotecan phase III trials. Ann Oncol 15:1013-1017, 2004

26. Extermann M, Boler I, Reich RR, et al: Predicting the risk of chemotherapy toxicity in older patients: The Chemotherapy Risk Assessment Scale for High-Age Patients (CRASH) score. Cancer 118:3377-3386, 2012

27. Hurria A, Togawa K, Mohile SG, et al: Predicting chemotherapy toxicity in older adults with cancer: A prospective multicenter study. J Clin Oncol 29:3457-3465, 2011

28. Mohile SG, Bylow K, Dale W, et al: A pilot study of the vulnerable elders survey-13 compared with the comprehensive geriatric assessment for identifying disability in older patients with prostate cancer who receive androgen ablation. Cancer 109:802-810, 2007

29. Bellera CA, Rainfray M, Mathoulin-Pélissier $S$, et al: Screening older cancer patients: First evaluation of the G-8 geriatric screening tool. Ann Oncol 23:2166-2172, 2012

30. Molina-Garrido MJ, Guillén-Ponce C: Overvaluation of the vulnerable elders survey-13 as a screening tool for vulnerability. J Clin Oncol 29: 3201-3202, 2011 